\title{
Who Needs the Dark Web? Exploring the Trade in Critically Endangered Plants on eBay
}

\author{
Robert Todd Perdue ${ }^{1}$ (D) \\ Received: 18 December 2020 / Accepted: 22 June 2021 / \\ Published online: 19 November 2021 \\ (c) Southern Criminal Justice Association 2021
}

\begin{abstract}
Stemming the illegal trade of endangered species is a critical and very difficult challenge for conservationists and law enforcement. Much effort is given to stopping the trade of "charismatic megafauna" such as tigers, elephants, and rhinoceroses. Endangered plant species, however, receive far less attention and fewer resources, resulting in devastating consequences. Plant species continue to go extinct due to illegal harvesting and selling, while just one order of plants, Orchidales, makes up more than $70 \%$ of all threatened wildlife species. This study examines the role the Internet plays in critically endangered plant transactions. Rather than focusing on the dark web for these sales, I search the e-commerce site eBay to better understand the extent to which these trades take place in plain sight. Of the 193 critically endangered plant species examined, 56 were for sale in some form on eBay during the study period. These results indicate a high degree of trading in these species, but do not necessarily indicate criminality. The complexity of the international legal frameworks regulating these transactions makes it difficult to ascertain their legality, but certain indicators point to at least a subset of these sales being unlawful. E-commerce sites like eBay must take more proactive measures to regulate sales and protect these species on the brink, for it is clear the surface web is playing an understudied and important role in fostering these cybercrimes. In sum, the dark web is unnecessary when the surface web is convenient, widely available, and scarcely policed.
\end{abstract}

Keywords Green criminology $\cdot$ Cybercrime $\cdot$ Endangered species · Orchids $\cdot$ Black market · Wildlife

Robert Todd Perdue

rperdue@elon.edu

1 Department of Sociology \& Anthropology, Elon University, Elon, NC, USA 


\section{Introduction}

The illegal trade in wildlife receives much deserved attention. Images of rhinos dehorned and dead on the ground, orangutans in cages, and confiscated elephant tusks set ablaze pull on the heart strings of global citizens. COVID-19 has thrust humanity's exploitation of wild animals to the fore as the pangolin, a unique, endangered species coveted in Chinese medicine, leapt to the front page as a potential source of the virus. While stemming such illegal wildlife trading is crucial, the magnetism of fauna such as elephants and pangolins overshadows the dire status of critically endangered flora. Indeed, just one order of plants, Orchidales, makes up more than $70 \%$ of the threatened species list compiled by the Convention on the International Trade in Endangered Species of Wild Flora and Fauna (CITES) (Hinsley, 2018). The privileging of animals over plants is not surprising, as it seems a near universal tendency to treat plants as merely the background to animal life, a concept encapsulated by Wandersee and Schussler (1999) as "plant blindness." This oversight has significant impacts, however, as critically endangered plants receive significantly less conservation resources and attention than "charismatic megafauna," and myriad plants go extinct every year.

While green criminologists have long recognized the need to combat the trade in illegal wildlife (Beirne \& South, 2013; Brisman \& South, 2014; Lynch \& Stretesky, 2014), only recently has attention turned to the potential of the Internet as a conduit and facilitator of these black markets (Harrison et al., 2016). Cybercrime research has found the web to be a robust market for buying and selling illicit goods, from drugs, to pornography, to virtually anything in between (Jardine \& Lindner, 2020; Marcum \& Higgins, 2019). The role the Internet plays in connecting buyers and sellers of illegal wildlife is still murky, however, and this paper aims to shed more light on the extent of such crimes. Rather than seek out such transactions on the dark web (DW) I take a different approach, exploring the trade in critically endangered plants on the surface web, asking: to what extent are some critically endangered plants available for sale on eBay? Searching for vulnerable flora on this open platform reveals that some cybercrimes may be hidden in plain sight.

\section{Wildlife Trading on the Internet}

Only recently have scholars begun exploring the role of the Internet in facilitating the illegal trade in wildlife, and these studies have yielded mixed results. Seeking to assess the extent and nature of the trade on the DW, Harrison et al. (2016) archived nearly ten thousand individual posts and searched within them a list of one hundred twenty-one keywords associated with the trade. All of this effort yielded only one "hit" linked to an endangered species: a potential sale of the hallucinogenic San Pedro cactus. Several methodological issues surfaced in their investigation. For instance, problems surrounding key word searches quickly emerged, as most of their hits referenced other products, i.e. "ivory" was linked to the drug 2-DPMP, while "tiger" referred to pornography. Other limitations 
centered on their inability to enter certain marketplaces, especially sites which required registration/login, employed CAPTCHAs (completely automated public Turing test, to tell computers and humans apart), or required human referrals. Despite these challenges, the researchers reached an important conclusion that guides this study, explaining: "This negligible level of activity related to the illegal trade of wildlife on the dark web relative to the open and increasing trade on the surface web may indicate a lack of successful enforcement against illegal wildlife trade on the surface web" $(2016,2)$. This is a critical point, as it is unclear why one would go to the trouble of using the dark web when the surface web is convenient, available to more customers, and scarcely policed.

The conclusion that law enforcement and scholars need to prioritize surface web investigations reinforces the findings of Hernandez-Castro and Roberts (2015). As computer scientists, the authors were able to develop an automated system to detect potentially illegal ivory sales on eBay. They set out to compare their program's efficacy to that of law enforcement officers with expertise in elephant ivory identification tasked with scouring the "Antiques" section of the platform for two months. Their computer analysis was nearly as effective as the experts, suggesting that some of the tedious and time consuming work required to scour the Internet for wildlife trading could be automated, but more importantly, their study reinforced the fact that illegal wildlife transactions were taking place in plain sight on eBay.

With regard to illegal flora trading, Phelps and Webb (2016) examined the undocumented illegal trade of wild ornamental plants in Southeast Asia, a study they contend was the first of its kind. Their botanical surveys "revealed a massive, previously undocumented commercial trade in wild, protected ornamental plants involving Thailand, Laos and Myanmar... [which] identified 347 orchid species in 93 genera, including many listed as threatened" $(2015,296)$. The study is notable for its on-the-ground methodology which included botanical surveys of plant markets across Thailand as well as interviews with traders. The study underscores the immense demand for rare orchids, especially in southeast Asia where most species are endemic and culturally significant.

One of the preeminent scholars examining illegal flora trading, Amy Hinsley, has also found intense demand for orchids, and is one of the few who has examined plant trading on e-commerce sites (Hinsley, 2016). Hinsley, Lee, et al. (2016b) examined the role of social media in the global trade, finding nearly half of sales were in wildcollected plants. She argues that online trading should be of great concern to conservationists, as sellers seeking to bypass CITES regulations turn to direct-to-consumer sales (Hinsley, Nuno, et al., 2016c). Advertising plants as rare and exotic, sellers look to entice buyers to purchase potentially unlawful plants (Hinsley et al. 2015). In one notable case, a newly discovered species of lady slipper orchid (Paphiopedilum canhii) was nearly driven to extinction after intense demand (much of it Internet-based) resulted in $99 \%$ of known plants being collected within 6 months of discovery (Hinsley, 2018). Especially vexing for those aiming to thwart such rapaciousness is the fact that both legal and blackmarket plant traders use similar methods and networks, with many dealers involved in both legal and illegal dealings (ibid). Her overarching conclusion points to the need for much additional study: "Very little research has been carried out into the status, characteristics or networks of the offline or online illegal orchid trade, so conclusions about trends are difficult to draw" (Hinsley, 2018, 4). 
While orchids have garnered the majority of the limited attention dedicated to illegal flora trading, medicinal plants are also vulnerable to overharvesting and trade on e-commerce sites. Perhaps not surprisingly, many of these species are endangered because of their supposed usefulness in maintaining and supplementing male vitality. In 2017, CITES produced a study examining the sale of endangered medicinal plant species on eBay, as well as the e-commerce platform Amazon. Similar to other studies examining plants and online markets, the work is complicated by the various parts of plants that can be sold separately and for different uses, such as leaves, flowers, roots, rhizomes and so on. Nevertheless, the study concluded that twenty-six plants needed further study because of high demand and traffic on the platforms (CITES, 2017).

In short, it is clear that illegal wildlife trading, especially that surrounding flora, demands focused and sustained attention. Scholars have found endangered plants, especially orchids and medicinal plants, for sale on e-commerce platforms such as eBay. This study aims to contribute to our understandings of the extent of such illegal wildlife trading on the surface web, as many scholars exploring such markets ask: who needs the dark web?

\section{Methods}

The goal of this study is to shed light on illegal wildlife trading by examining the extent to which two categories of endangered plants are available for sale on eBay. Founded in 1995, eBay Inc. is the industry leader in consumer-to-consumer and business-to-consumer sales. Its online auction and shopping features have helped the company become a multibillion dollar juggernaut with global operations (Statistica, 2020). This last point is especially important for this study, as many of the plants under investigation here are native to Asia and the trade is international in scope. The strategic choice to focus on eBay is influenced by the 2017 study conducted by CITES, which found more flora traffic on eBay than on Amazon (CITES, 2017).

That study also directs the sample composition used in this research. The authors concluded that twenty-six species (or families) required further scrutiny because of "high demand in medicinal products made of those species" (CITES, 2017, 35). As such, these twenty-six plants make up the first group of plants investigated in this study (Appendix Table 1). The second group of plants is composed of critically endangered members of Orchidaceae, a diverse family of flowering plants with over 870 genera and 28,000 species, commonly referred to as orchids (Govaerts et al., 2017; Swarts and Dixon 2009).

The work of Hinsley and colleagues suggest that orchids are the most commonly traded endangered plant species, thereby giving us insight into the extent of trading in online surface markets (Hinsley et al. 2018). Orchids are imperiled worldwide, making up more than $70 \%$ of the 35,000 threatened wildlife species listed by CITES (ibid). While some covet certain orchids for medicinal use, it is the near limitless variation in flower shape, size and color that make orchids coveted globally. In addition to threats from overcollection, these plants are threatened by many of the same anthropogenic extinction drivers faced by other wildlife, such as logging, road building, and forest plantations (Gale et al., 2018). 
In their most recent assessment, International Union for Conservation of Nature (IUCN) lists 2493 "critically endangered" plant species. This category represents the most vulnerable plants in the world with the next step being "extinct in the wild." IUCN lists 167 species of orchids as critically endangered, many of which are also listed with the caveat "possibly extinct in the wild" (IUCN 2016). This list of critically endangered orchid species makes up our second sample for examination (Appendix Table 2).

These two samples, 26 medicinal species (and families) of concern according to CITES, and 167 critically endangered orchid species listed by IUCN, were searched for on eBay in November 2020. It is important to note that by its very nature e-commerce is dynamic, with items constantly bought and sold; this study examines one snapshot in time. Nevertheless, this snapshot should provide us a look into the broader patterns of surface web trading. Other analytic decisions had to be made, with one important choice being to search using scientific names. As such, I follow the methodology employed by CITES (2017) in their examination of medicinal plants for sale on the Internet, with the understanding that some amount of transactions made using common plant names may have been overlooked. I contend, however, that with the vast amount of plant species (especially within the Orchidacea family), buyers and sellers are likely to use scientific names to be as specific and targeted in their advertising and searches as possible.

A spreadsheet with all species under study was constructed, with columns noting: (1) whether the species was for sale on eBay, (2) if the plant was for sale, how many specimens were listed, (3) the price range of plants, (4) the seller's eBay handle, and (5) any notes of interest, such as whether the specimen was being sold from overseas.

\section{Results}

The examination revealed a significant proportion of plant species available for purchase on eBay. Of the 167 orchid species examined, 41 had some sort of plant product for sale on eBay. Prices ranged from $\$ 7.95$ up to $\$ 369.99$ for a Paphiopedilum gigantifolium. Five of the 41 species found were advertised as "CITES", one as "rare,"and another as "very rare." Eight of the 41 species were being sold from Thailand.

Of the twenty-six medicinal species (or families), fifteen had some sort of plant product (seeds, seedlings, plants, etc.) for sale on eBay. Prices ranged from just a few dollars to \$2899.99 for fifty pounds of Panax Ginseng seeds. Many more specimens were listed in this sample, presumably because CITES listed entire families of plants (ie. Aloe spp., Cactaceae spp). Numerous plants were advertised as "rare," "very rare," or "exotic." Indeed, seeds for one cactus (Eulychnia Acida Cactaceae) available from Israel were advertised as "endangered species." Of the fifteen plant species (or families) found on eBay, all but one (Euphorbia antisyphilitica) were marketed from both inside and outside of the United States. While Thailand was the predominant location of international orchid sales, a diverse array of nations were represented in the medicinal plant trade, including Australia, China, Hungary, India, Israel, Italy, Malta, Poland, and Russian Federation. 


\section{Discussion}

Making sense of such findings is not a straightforward process for either of the samples examined. This is due in large part to the complexity of the international legal frameworks which have differing standards for specific plants, for different parts of plants, for wild vs. cultivated plants, and for international compared to national trading, among other variants (Hinsley, 2018). In short, although numerous endangered plants were for sale on eBay, it is difficult to ascertain the legality of these sales.

Because of the vulnerability of orchids, CITES has established strict guidelines for the orchid trade, creating two categories tied to the perceived vulnerability of individual species, so-called Appendices Tables 1 and 2. Most legally traded orchids fall under the auspices of Appendix Table 2, the less stringent of the two categories, which allows for commercial trade. Such trading does, however, require import and export permits as well as evidence that the export of these plants will not be detrimental to species survival, among other stipulations. On the international scale all orchids are listed by CITES, with most listed in Appendix Table 2, meaning that international shipment, either wild or artificially propagated, requires appropriate CITES paperwork. As Hinsley et al. $(2018,440)$ note: "Although some exceptions have been made for certain types of orchid material...the international movement in most orchids, whether for personal, commercial or scientific purposes, must be monitored and sanctioned by the relevant CITES agencies."

It is unclear whether these international sellers, of which many were identified in this analysis, are adhering to these protocols. Indeed, no seller found it necessary or desirable to advertise their adherence to CITES regulations in their advertisements. Put simply, sellers are committing crimes if they are not following such protocols, but only with the purchase of plants could we verify the legitimacy of these sales. More doubt is cast on the legality of these sales by the descriptors used to advertise these plants. As noted, some orchids were labeled as "rare" and "CITES." This could point to cybercrime, for as Hinsley $(2018,11)$ notes, "NNew species', "very rare' and worldwide shipping are indicators of illegal activity."

The other category developed by CITES, Appendix Table 1, is for plants of more concern. Six orchid species are listed in this Appendix, as well as the entire genera Paphiopedilum (lady slippers) and Phragmipedium. Of the 167 orchids examined, forty-five were Paphiopedilum, with twenty-five available for purchase on eBay. Ten of the 167 critically endangered orchids were Phragmipedium, with four of these for sale on the e-platform. In sum, twenty-nine Appendix Table 1 listed specimens were for sale on eBay. Five species of Paphiopedilum were being sold from Thailand, which could indicate criminality, as all international commercial trade is illegal, according to Appendix Table 1, unless the material is artificially propagated from legally obtained founder stock (Hinsley et al. 2018). Again, however, it is difficult to discern if these plants are being traded illegally, as it is unclear how these plants were propagated and no details are provided. Moreover, no eBay sellers displayed plants in the wild or recently harvested plants, many opting for stock photos. It is important to note, however, scholars have found that many sellers and buyers participate in both legal and illegal trades simultaneously, making it very difficult to 
discern in which cases criminality is occurring; legal trades can serve as a vetting process of sorts for buyers and sellers looking to engage in future unlawful trades.

It is nearly as difficult to discern criminality in the medicinal plant sample. These are CITES listed plants and the same regulations are applied to these plants as the orchids, and the same difficulties in ascertainment apply. For instance, of the fifteen species found for sale on eBay, all but one had listings from abroad. As such, all of the international protocols and restrictions are required, but yet again it is unclear if these regulations are being followed. Moreover, and similar to the orchid trade, verbiage that other scholars suggest are warning signs ("rare", "exotic", etc.) was also present in the medicinal plant advertisements.

In sum, it is important to note that within the endangered flora realm, it is often not the species which make a sale illegal, but rather whether the proper bureaucratic channels and protocols have been followed, whether the sale crossed international boundaries, and whether the plant was wild harvested. Even with this information, some nations are erratic in their regulation and inconsistent in their enforcement, often because of a lack of resources. All in all the opaqueness found here has resulted in thousands of trades in critically endangered plants on the surface web whose legality is cloudy at best.

\section{Conclusion}

This study has found that numerous critically endangered plants are for sale on eBay. Despite this fact, it is altogether unclear if the Internet has been used to facilitate illegal trading in wildlife in this context. Numerous challenges are present in such determinations, chief among them the complexity and variability of legal frameworks regulating these flora markets. This is clearly a liability in efforts to conserve these endangered plants, as nebulous regulations provide traders plausible deniability, limits serious enforcement, and fosters illegal sales. Indeed, a major challenge outlined by numerous researchers is that many sellers engage in both legal and illegal sales, presenting a significant hurdle to law enforcement efforts. With that said, this examination does reveal certain elements that hint at illegality, including provocative descriptions of plants as "rare" or "endangered," as well as the international nature of the trade with no assurance of adherence to CITES protocols.

This study was limited in some important ways by methodological choices, such as using scientific names as key words, and by practical ones, such as an inability to actually purchase these plants to determine seller adherence to protocols. Nevertheless, many avenues for new and continued study have become evident. It is clear that critically endangered plants are available online, which underscores the power of the Internet to connect buyers and sellers that would have been required to meet offline at international orchid shows in the past. More research is needed to investigate plant sales on other digital platforms, as social media appears to be an increasingly important space for such trades. Hinsley (2018) notes that sales are appearing in newer spaces such as Instagram, suggesting that unwanted attention to eBay and Amazon sales by researchers may be redirecting the market to new realms. Shedding light on the relationship between illegal wildlife trading and social media is a needed next step. Moreover, 
information about sellers on e-commerce spaces is available, but information about buyers is virtually non-existent. This is a challenging but necessary line of research that could unlock many of the mysteries surrounding illegal flora trading.

Finally, the trade in domestically propagated plants dwarfs that of illegally harvested wild-harvesting. Trade in these plants could actually be a benefit to conservation if plants are cultivated from appropriate stock, helping to protect species from extinction by adding to their numbers. Nevertheless, the trade in wild plants is well documented in numerous countries, but the scale and nature of this trade is unknown (Hinsley, 2018). Scholars and conservationists will need to summon creativity to ascertain the extensiveness of this devastating market, and will need to muster substantial resources to quell it. Future work is needed to evaluate the role the dark web plays in these black markets, but for now it is clear the surface web is playing an understudied and important role in fostering these cybercrimes.

\section{Appendix}

Table 1 CITES listed medicinal plants of concern

\begin{tabular}{ll}
\hline Aloe spp. & Guaiacum spp. \\
Aloe arborescens & Panax ginseng \\
Aloe ferox & Panax quinquefolius \\
Aloe perryi & Cactaceae spp. \\
Hoodia spp. & Opuntia ficus-indica \\
Rauvolfia serpentina & Saussurea costus \\
Orchis mascula & Diospyros spp. \\
Phalaenopsis amabilis & Euphorbia spp. \\
Vanilla planifolia & Euphorbia antisyphilitica \\
Cistanche deserticola & Prunus Africana \\
Hydrastis canadensis & Aquilaria spp. \\
Cyclamen spp. & Nardostachys grandiflora \\
Picrorhiza kurrooa & Guaiacum officinale \\
\hline
\end{tabular}




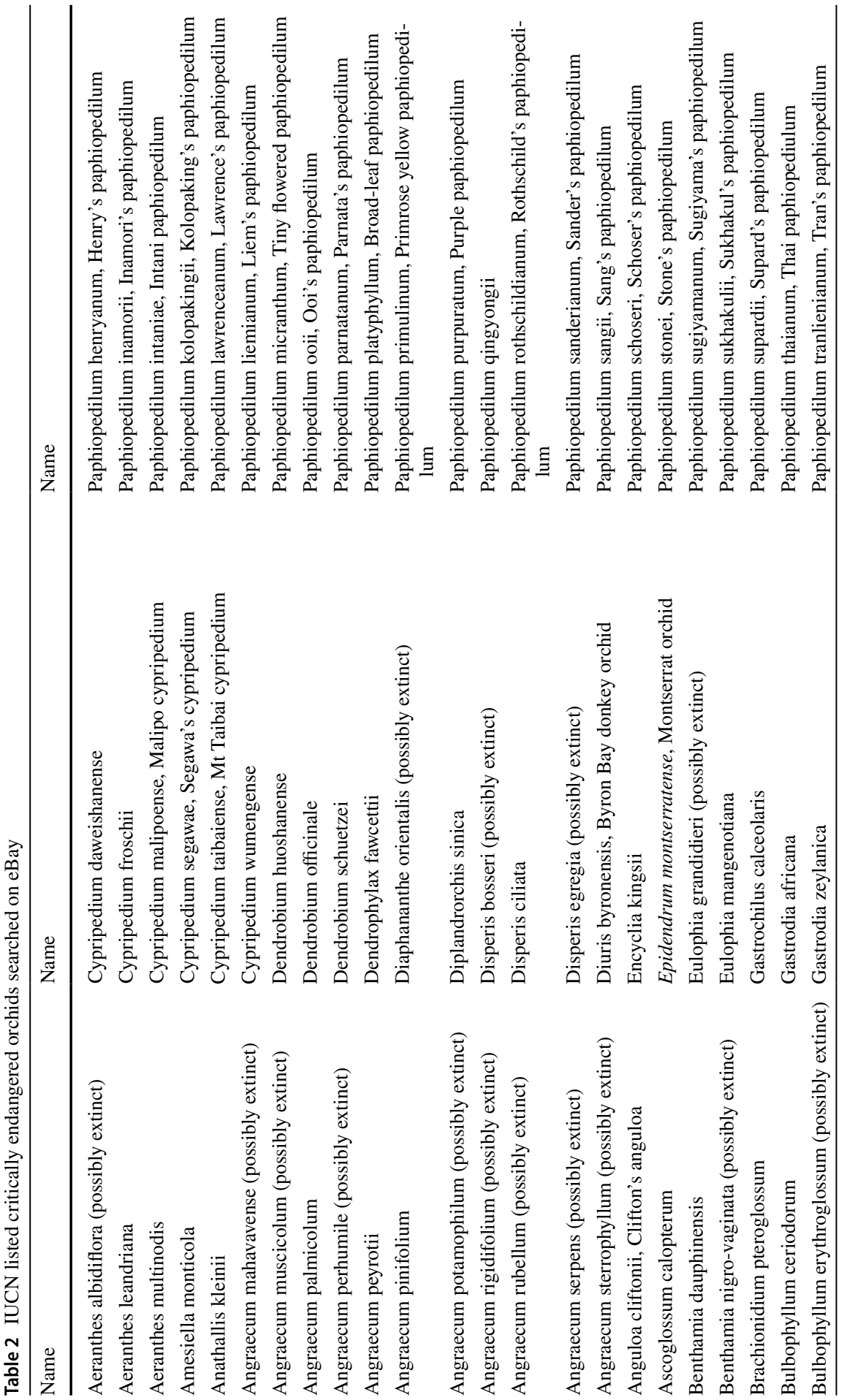




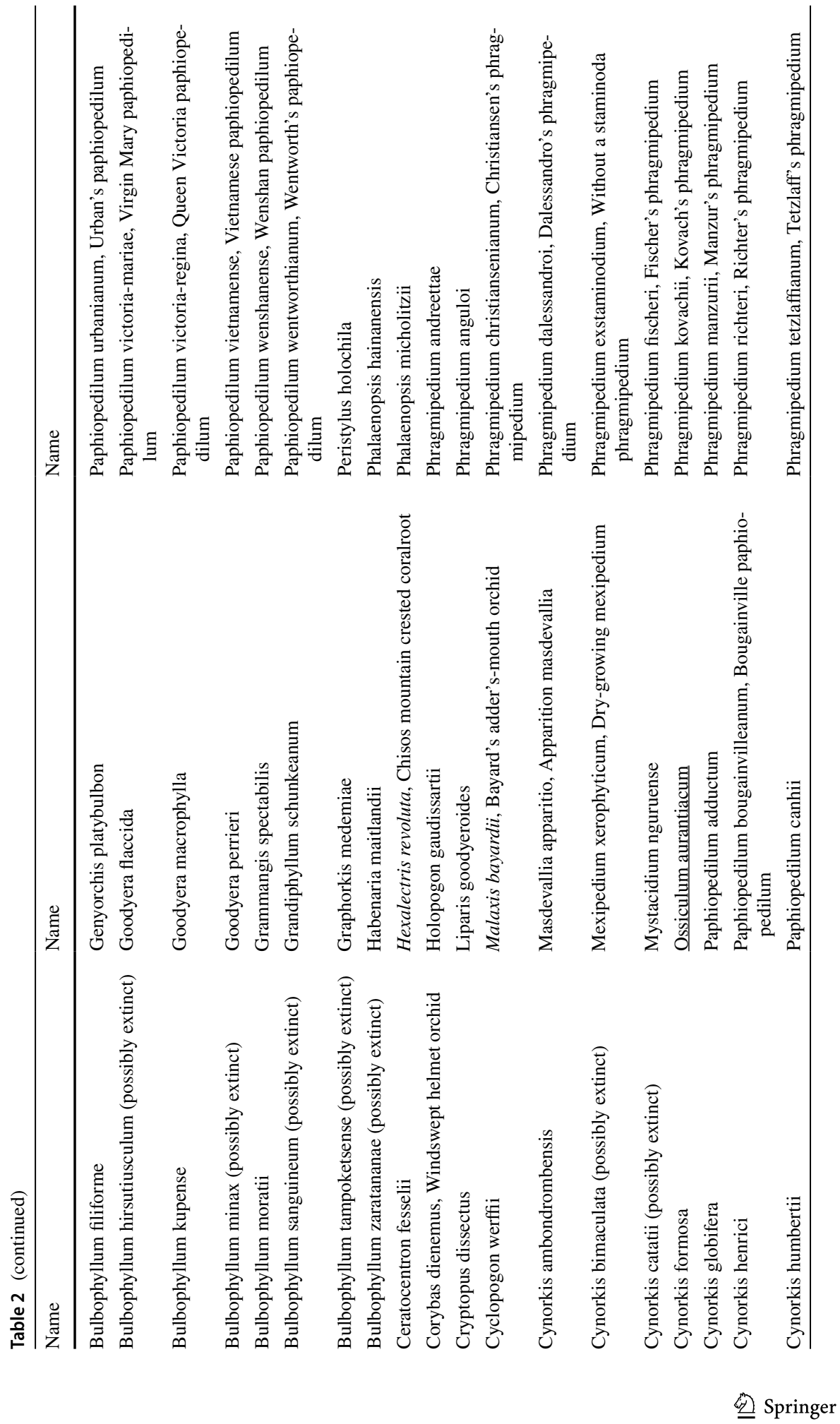




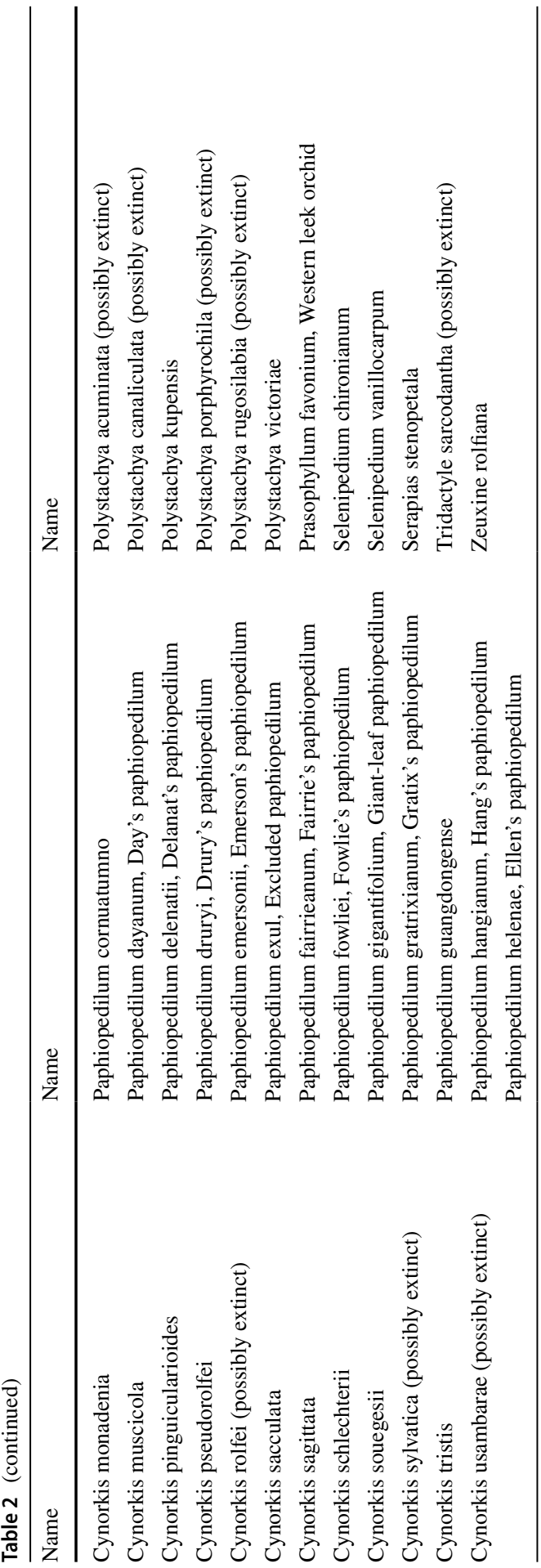




\section{References}

Beirne, P., \& South, N. (2013). Issues in green criminology: Confronting harms against environments, humanity and other animals. Routledge.

Brisman, A., \& South, N. (2014). Green cultural criminology: Constructions of environmental harm, consumerism, and resistance to ecocide. Taylor and Francis.

Convention on the International Trade in Endangered Species of Wild Flora and Fauna (CITES). (2017). CITES-listed medicinal plant species. Geneva, Switzerland, 1-39.

Gale, S. W., Fischer, G. A., Cribb, P. J., \& Fay, M. F. (2018). Orchid conservation: Bridging the gap between science and practice. Botanical Journal of the Linnean Society, 186, 425-434.

Govaerts, R., Bernet, P., Kratochvil, K., Gerlach, G., Carr, G., Alrich, P., Pridgeon, A. M., Pfahl, J., Campacci, M. A., Holland, B. D., Tigges, H., Shaw, J., Cribb, P., George, A., Kreuz, K., \& Wood, J. (2017). World checklist of Orchidaceae. Facilitated by the Royal Botanic Gardens http://wcsp.scien ce.kew.org

Harrison, J. R., Roberts, D. L., \& Hernandez-Castro, J. (2016). Assessing the extent and nature of wildlife trade on the dark web. Conservation Biology, 30(4).

Hernandez-Castro, J. R., \& Roberts, D. L. (2015). Automatic detection of potentially illegal online sales of elephant ivory via data mining. PeerJ Computer Science, 1, e10.

Hinsley, A. (2016). Characterising the structure and function of international wildlife trade networks in the age of online communication. Ph.D. Thesis, University of Kent.

Hinsley, A. (2018). A review of the trade in orchids and its implications for conservation. Botanical Journal of the Linnean Society, 186, 435-455.

Hinsley, A., King, E., \& Sinovas, P. (2016a). Tackling illegal wildlife trade by improving traceability: A case study of the potential for stable isotope analysis. In G. Potter, A. Nurse, \& M. M. Hall (Eds.), The geography of environmental crime (pp. 91-119). Palgrave Macmillan UK.

Hinsley, A., Lee, T. E., Harrison, J. R., \& Roberts, D. L. (2016b). Estimating the extent and structure of trade in horticultural orchids via social media. Conservation Biology, 30, 1038-1047.

Hinsley, A., Nuno, A., Ridout, M., St. John, F. A., \& Roberts, D. L. (2016c). Estimating the extent of CITES noncompliance among traders and end-consumers: Lessons from the global orchid trade. Conservation Letters, 10, 602-609.

Jardine, E., \& Lindner, A. M. (2020). The dark web and cannabis use in the United States: Evidence from a big data research design. International Journal of Drug Policy, 76.

Lynch, M.J., \& Stretesky, P.B. (2014). Exploring green criminology: Toward a green criminological revolution. .

Marcum, C. D., \& Higgins, G. E. (2019). Cybercrime. In M. Krohn, N. Hendrix, N. Cham, G. P. Hall, \& A. J. Lizotte (Eds.), Handbook on crime and deviance (pp. 459-475). Springer.

Phelps, J. (2015). A blooming trade: Illegal trade of ornamental orchids in mainland Southeast Asia (Thailand, Lao PDR, Myanmar). TRAFFIC.

Phelps, J., Hinsley, A., \& Maguiles, J. (2018). Illegal wildlife trading endangers plants-But few are listening. IUCN Blog https://www.iucn.org/news/species/201810/illegal-wildlife-trade-endangersplants-few-are-listening

Statistica. (2020). eBay-Statistics and facts. https://www.statista.com/topics/2181/ebay/

Swarts, N. D., Batty, A., Hopper, S., \& Dixon, K. W. (2007). Does integrated conservation of terrestrial orchids work? Lankesteriana, 7, 219-222.

Wandersee, J. H., \& Schussler, E. E. (1999). Preventing plant blindness. The American Biology Teacher, $61(2), 82-86$.

Publisher's Note Springer Nature remains neutral with regard to jurisdictional claims in published maps and institutional affiliations. 